\title{
Statistical Analysis of Corrosion Process Flow
}

\author{
Tomislav ŠOLIĆ, Sara HAVRLIŠAN, Dejan MARIĆ, Ivan SAMARDŽIĆ
}

\begin{abstract}
This paper presents the results of testing two different materials in aggresive atmosphere rich in sodium chloride (NaCl) depending on different time intervals (48, $96,168,240$ hours), in order to determine the corrosion process flow. One of the materials is general structural steel SA516 Gr.70 and the other is austenitic stainless steel X6CrNiTi18-10. The test results were statistically analyzed with the aim of obtaining statistical regression models, as well as to investigate the effect of alloying elements on the corrosion process flow. Models for predicting the corrosion process flow (mass loss) of both materials were obtanined by statistical analysis and it was determined that the proportion of alloying elements influences the change in the flow. Accordingly, general structural steel is characterized by linear, while austenitic stainless steel is marked by slow corrosion process flow. This indicates that the proportion of alloying elements which improve the corrosion resistance of the material strongly affects the durability of the material in an aggressive environment.
\end{abstract}

Keywords: corrosion process flow; regression analysis; salt chamber

\section{INTRODUCTION}

The damaging of structural materials by corrosion mechanisms poses a major problem in exploitation, causing a deviation from the dimensioned properties as well as a reduction of the total life span. The very process of formation of corrosion mechanisms, i.e. corrosion damage, can be characterized as a spontaneous heterogeneous chemical process in which the reactants are the environment (one or more of its components) and the structural material. Depending on the conditions of the processes, the products of the mentioned mechanisms also differ and may be of solid, gaseous or dissolved character [1-10].

The above mentioned exploitation properties mainly depend on the corrosion resistance of the particular material a certain structure is made from. One of the ways to preserve the dimensional properties of the structure is to select properly the structural material for the use in certain operating conditions. For example, if the structure or element is going to be used in environment such as the coastal atmosphere, it is necessary to know or establish the corrosion resistance of the material when it is exposed to sodium chloride. Furthermore, selecting the optimum construction material prevents material degradation, i.e. the mass loss caused by the appearance of corrosion mechanisms, which would result in a reduction of the required structure dimensions [11-13].

Assessment of the optimal material for application is possible by determining the corrosion process flow which determines its behavior under certain exploitation conditions. If the material is used in the coastal environment, its high moisture conditions represent a major factor in the formation of electrochemical corrosion mechanisms. Moreover, these conditions are also rich in sodium chloride inclusions, which are extremely aggressive and harmful to the durability of the material. In order to achieve such conditions, the test is carried out in a device called a salt chamber where samples are cyclically moistened by the fog of a 5\% sodium chloride solution [1419].

The statistical analysis that will determine the corrosion process flow can be made on the basis of the results obtained from the salt chamber test. Any corrosion process between the reactants of the environment and the structural material occurs only if there is a tendency to a spontaneous reaction between them. This tendency is called affinity, and the corrosion process flow depends on it as well as on the resistances to the process. Thus, it can be said that the affinity for the onset of corrosion processes is influenced by external and internal factors, the working environment as well as the structural material itself. Therefore, the corrosion process flow depends on the material, the aggressive environment that surrounds it, the corrosion products and the physical conditions under which the process takes place. Some of the most important factors influencing the corrosion process flow are certainly the structure and texture of the material and the composition and concentration of the environment. Since the composition and the concentration of the environment are constant under exploitation, in this case test conditions, then a factor that can be regulated is the structure of the material (chemical composition that directly influences the change in the corrosion process flow). If in the coordinate system the time during which test samples were exposed to an aggressive atmosphere is applied to the abscissa, and the mass loss for each individual test sample is applied on the ordinate, it is possible to obtain the corrosion process flow. It can be linear, slow, accelerated - linear, accelerated slow and discontinuous [2].

Therefore, if a particular material has a linear corrosion process flow in exploitation conditions, the option of selecting another material should be taken into consideration. By changing the chemical composition of the material (by the process of alloying), it is possible to improve the corrosion properties and resistance of the material to exploitation conditions and thus aspire to achieve a slow corrosion process flow. At the linear corrosion process flow, the material will constantly decay and lose mass, which will ultimately result in deviation from dimensioned properties and failure. On the other side, the slow corrosion process flow creates corrosion products that are sufficiently stable on the surface of the material (due to its more suitable chemical composition) and thus these products further inhibit the emergence of new corrosion mechanisms. This results in a slow decay of the structural material as well as an extension of its durability. 
The aim of this paper is to determine, through statistical analysis of experimental data, what is the effect of individual alloying elements on the corrosion behavior of the material. In other words, what would be the rate at which the corrosion process will progress or decrease depending on different time intervals of exposure to the aggressive sodium chloride $(\mathrm{NaCl})$ atmosphere.

\section{EXPERIMENTAL WORK}

Two different materials were used to perform the experimental investigations and determine the corrosion process flow under exploitation conditions rich in sodium chloride (aggressive salt chamber atmosphere). The reason for using two materials with different chemical composition is to determine the positive effect of alloying. The materials are alloyed in order to achieve better corrosion resistance, i.e. a more suitable pattern of the corrosion process flow that will ensure a longer construction life and longer provision of the required and dimensioned exploitation properties.

The first material used for testing is general structural steel SA516 Gr.70 whose chemical composition is shown in Tab. 1 [20].

Table 1 Chemical composition of steel SA516 Gr.70

\begin{tabular}{|c|c|c|c|c|c|}
\hline Chemical element & $\mathrm{C}$ & $\mathrm{Mn}$ & $\mathrm{P}$ & $\mathrm{Si}$ & $\mathrm{S}$ \\
\hline wt. / \% & 0,28 & $0,79-1,3$ & 0,035 & $0,13-0,45$ & 0,035 \\
\hline
\end{tabular}

The other material is austenitic stainless steel X6CrNiTi18-10. What makes it austenitic stainless steel is the proportion of alloying elements within the required limits that improve corrosion resistance. These elements should also ensure that the steel has a more favorable corrosion process flow than the previously mentioned. Tab. 2 shows the chemical composition of steel X6CrNiTi18-10 [21].

Table 2 Chemical composition of steel X6CrNiTi18-10

\begin{tabular}{|c|c|c|c|c|c|c|}
\hline Chemical element & $\mathrm{C}$ & $\mathrm{Mn}$ & $\mathrm{Si}$ & $\mathrm{Ni}$ & $\mathrm{Ti}$ & $\mathrm{Cr}$ \\
\hline wt. $/ \%$ & 0,01 & 1,79 & 0,53 & 9,56 & 0,15 & 17,05 \\
\hline
\end{tabular}

Test samples of general structural steel SA516 Gr.70 are cut from sheet metal to dimensions $60 \times 10 \times 13 \mathrm{~mm}$. There are eight test samples which will be exposed to the salt chamber atmosphere at different time intervals. After being cut, the samples were mechanicaly cleaned with waterproofing papers in order to remove corrosion products previously formed in the storage process.

Eight test samples from the austenitic stainless steel X6CrNiTi18-10 were cut to dimensions $150 \times 100 \times 0,3$ $\mathrm{mm}$, and after that they were also cleaned of impurities, greasy deposits and foreign bodies formed during treatment and preparation. The reason for cleaning all test samples is to ensure equal starting conditions for testing and thus ultimately more credible and accurate results as a basis for further processing and conclusions.

The salt chamber is a device for accelerated laboratory testing which is used for determination of the corrosion resistance of the material. It is used to conduct cyclical tests in which circumstances are programmed to achieve certain climatic conditions, such as coastal atmosphere. The conditions of the coastal atmosphere are achieved by cyclical moisturizing of the test specimens with a fog of
$5 \%$ sodium chloride $(\mathrm{NaCl})$ solution. The test itself is carried out in accordance with the standard HRN EN ISO 9227:2017 [22, 23]. The salt chamber parameters and atmospheric conditions set in the workspace are shown in Tab. 3.

Table 3 Salt chamber test parameters according to HRN EN ISO 9227:2017

\begin{tabular}{|l|c|}
\hline Test chamber temperature, ${ }^{\circ} \mathrm{C}$ & $35 \pm 2$ \\
\hline Temperature of compressed air humidifier, ${ }^{\circ} \mathrm{C}$ & $45-50$ \\
\hline Compressed air pressure, bar & $0,7-1,4$ \\
\hline Solution & $\mathrm{NaCl}$ \\
\hline Solution concentration of $\mathrm{NaCl}, \%$ & 5 \\
\hline pH condensate value at $25 \pm 2{ }^{\circ} \mathrm{C}$ & $6,5-7,2$ \\
\hline
\end{tabular}

The exposure time of the test samples to the salt chamber atmosphere was also defined and selected in accordance with the standard HRN EN ISO 9227:2017. Two test samples of both test materials were placed at each of the selected time intervals of $48,96,168$, and 240 hours.

Figs. 1 and 2 show test samples.

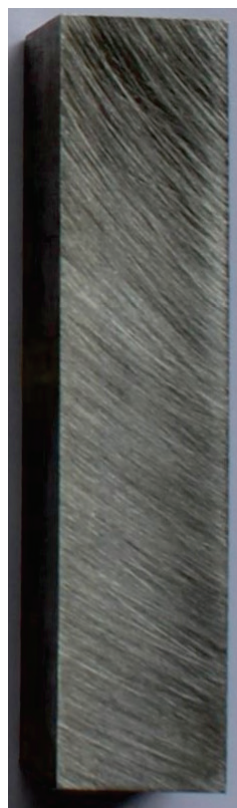

Figure 1 Test sample made of steel SA516 Gr.70

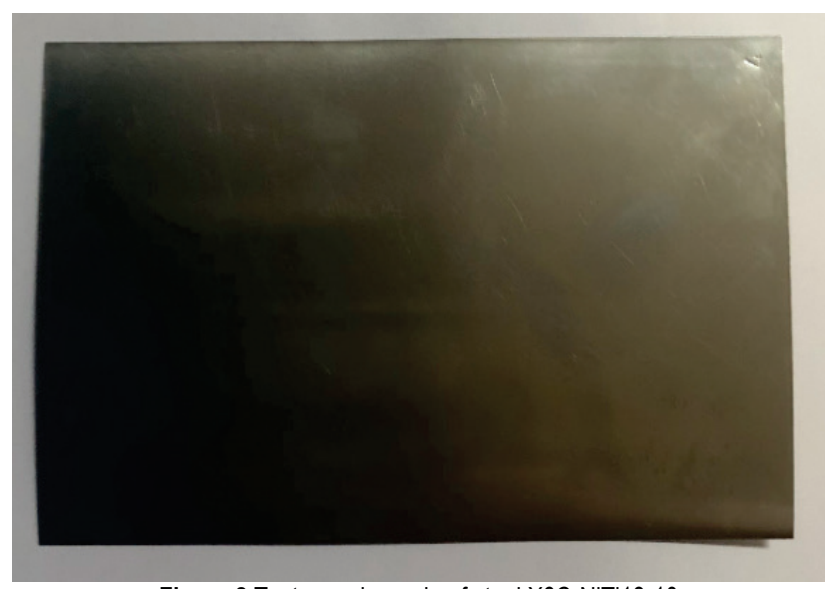

Figure 2 Test sample made of steel X6CrNiTi18-10

Increasing the exposure time is aimed at demonstrating how the corrosion process will develop and how much of the mass loss will depend on the testing time. In addition, it is aimed at showing what kind of corrosion process is involved in each of the test materials. 


\section{RESULTS AND DISCUSSION}

The input variable is defined by time trials $(t / \mathrm{h})$ in the salt chamber, while the output variable is the mass loss $(\Delta m$ $/ \mathrm{g}$ ) due to the exposure of a single sample to the aggressive atmosphere of the salt chamber.

Before being placed in the salt chamber, the test samples were weighed on a Scaltec SPB32 laboratory scale with a measuring range up to 120 grams and a precision of $10^{-4}$ grams. After removing the samples from the salt chamber, the next step was cleaning the corrosion products and residual accumulations of sodium chloride formed during the test. The test samples were then weighed again, and the difference in the obtained values of the weighing before and after the test in the salt chamber gave the values of mass loss.

The mass loss values of steel SA516 Gr.70 and X6CrNiTi18-10 (which are obtained according to Eq. (1) are shown in Tabs. 4 and 5.

$\Delta m=m_{1}-m_{2}$

Where is: $m_{1} / \mathrm{g}$ - the mass of the sample before placing it in the salt chamber; $m_{2} / \mathrm{g}$ - the mass of the sample after placing in the salt chamber; $\Delta m / \mathrm{g}$ - mass loss.

\begin{tabular}{|c|c|c|c|c|}
\hline 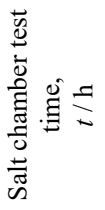 & 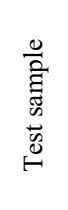 & 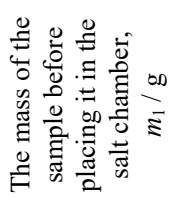 & 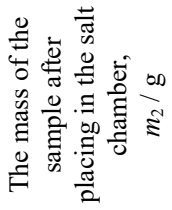 & 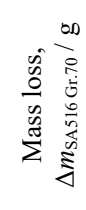 \\
\hline \multirow{2}{*}{48} & $1-1$ & 83,6487 & 83,5444 & 0,1043 \\
\hline & $1-2$ & 85,6584 & 85,5474 & 0,111 \\
\hline \multirow{2}{*}{96} & $1-3$ & 92,1983 & 92,0081 & 0,1902 \\
\hline & $1-4$ & 87,5264 & 87,3126 & 0,2138 \\
\hline \multirow{2}{*}{168} & $1-5$ & 91,7637 & 91,4545 & 0,3092 \\
\hline & $1-6$ & 88,9763 & 88,6480 & 0,3283 \\
\hline \multirow{2}{*}{240} & $1-7$ & 89,5846 & 89,1171 & 0,4675 \\
\hline & $1-8$ & 88,1209 & 87,6331 & 0,4878 \\
\hline
\end{tabular}

\begin{tabular}{|c|c|c|c|c|}
\hline 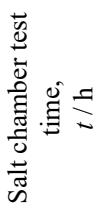 & 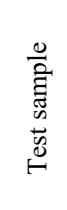 & 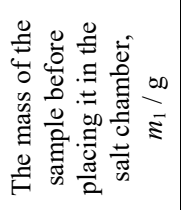 & 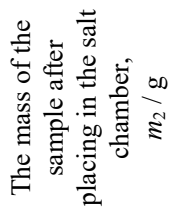 & 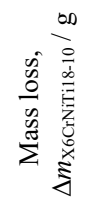 \\
\hline \multirow{2}{*}{48} & $2-1$ & 35,1306 & 35,1297 & 0,0009 \\
\hline & $2-2$ & 34,8465 & 35,8458 & 0,0007 \\
\hline \multirow{2}{*}{96} & $2-3$ & 34,9160 & 34,9143 & 0,0017 \\
\hline & $2-4$ & 35,3426 & 35,3411 & 0,0015 \\
\hline \multirow{2}{*}{168} & $2-5$ & 34,9189 & 34,9163 & 0,0026 \\
\hline & $2-6$ & 34,9231 & 34,9207 & 0,0024 \\
\hline \multirow{2}{*}{240} & $2-7$ & 34,9318 & 34,9291 & 0,0027 \\
\hline & $2-8$ & 34,2712 & 34,3690 & 0,0022 \\
\hline
\end{tabular}

\subsection{Regression Analysis}

Statistical software Statistica (version 13.4.0.14.) was used for graphical representation and statistical analysis of the experimental data presented in Tabs. 4 and 5, i.e. for obtaining regression models and analysis of model variance.
Fig. 3 graphically shows the results of the mass loss of steel SA516 Gr.70 depending on the time (Tab. 4), where it is evident that with an increase in time, there is an increase in mass loss (linear corrosion process flow).

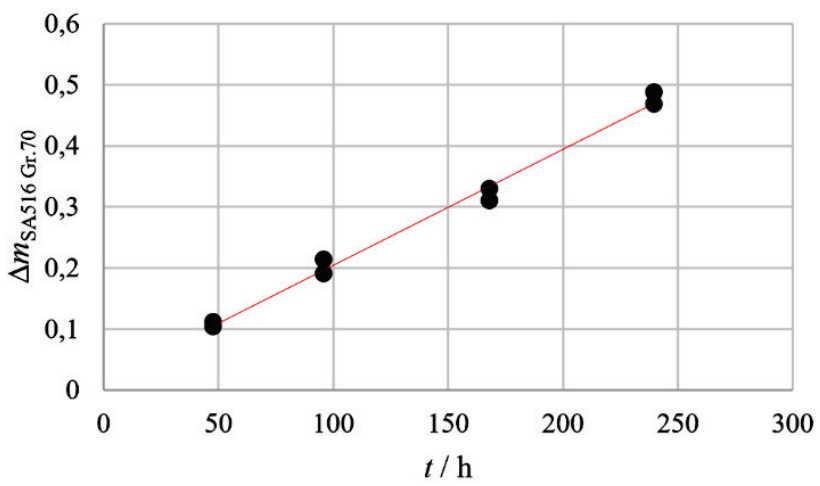

Figure 3 Graphic representation of the mass loss of steel SA516 Gr.70

After analysis of experimental data for steel SA516 Gr.70 there was obtained linear regression model (Eq. (2)).

$\Delta m_{\mathrm{SA} 516 \mathrm{Gr} .70}=0,015+0,0019 \cdot t$

There is also performed the analysis of variance (shown in Tab. 6) in order to check the adequacy of the obtained linear regression model (Eq. (2)).

Table 6 Analysis of variance for model - mass loss of steel SA516 Gr.70

\begin{tabular}{|c|c|c|c|c|c|}
\hline Effect & $\begin{array}{c}\text { Sum of } \\
\text { squares }\end{array}$ & $d f$ & Mean squares & $F$ value & $p$ value \\
\hline Regression & 0,152006 & 1 & 0,152006 & 703,2732 & $<0,0001$ \\
\hline Residual & 0,001297 & 6 & 0,000216 & & \\
\hline Total & 0,153303 & 7 & & & \\
\hline
\end{tabular}

From Tab. 6 it is evident that the probability ( $p$ value) for the calculated value of $F(703,2732)$ for the model is less than 0,0001 and less than the error of the first type $\alpha$ $(0,05)$, which indicates that the obtained model is significant. The model will well predict the time-dependent mass loss of steel SA516 Gr.70 when it is exposed to sodium chloride-rich aggressive atmosphere. The coefficient of determination $R^{2}$ is 0,9915 .

For the second test material (austenitic stainless steel X6CrNiTi18-10) the results of mass loss are shown in Fig. 4 (Tab. 5).

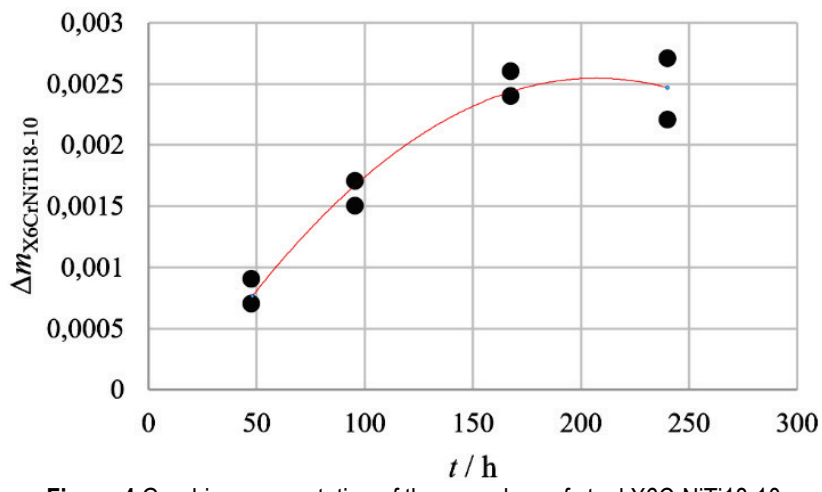

Figure 4 Graphic representation of the mass loss of steel X6CrNiTi18-10

Fig. 4 shows that with the increase in time, there is an increase in mass loss, which stagnates in the time interval from 168 to 240 hours. This indicates that the corrosion 
process flow is slowing down due to the formation of corrosion-resistant oxide, inhibiting further reaction.

The following regression model of steel X6CrNiTi1810 (Eq. (3)) was obtained by statistical analysis of the data in Tab. 5.

$$
\Delta m_{\mathrm{X} 6 \mathrm{CrNiTi18}-10}=-0,0005+3 \times 10^{-5} \cdot t-7 \times 10^{-8} \cdot t^{2}
$$

The obtained model is significant, so it will well predict the mass loss due to the exposure of X6CrNiTi1810 steel to the aggressive sodium chloride rich atmosphere. That was confirmed by analysis of variance of the obtained model (Eq. (3)). The probability ( $p$ value) for the calculated value of $F(46,561)$ for the model is 0,00005 and it is less than the error of the first type $\alpha(0,05)$. The coefficient of determination $R^{2}$ for the obtained model is 0,949 .

\subsection{Testing Hypotheses}

In this section, the aim is to test the hypotheses about the equality of arithmetic means and examine whether the proportion of alloying elements influences the mass loss, i.e. the corrosion process flow. MS Excel 2013 (Data Analysis tool) was used to test the hypotheses. Average mass loss value of steel SA516 Gr.70 $\left(\mu_{1}\right)$ is $0,2765 \mathrm{~g}$, while the average mass loss value of steel X6CrNiTi18-10 $\left(\mu_{2}\right)$ is $0,0018 \mathrm{~g}$.

Hypotheses have been defined. The null hypothesis $H_{0}$, which states that the average values of mass loss for both materials are equal $\left(\mu_{1}=\mu_{2}\right)$, and the alternative hypothesis $H_{1}$, which says that the average values of mass loss are different $\left(\mu_{1} \neq \mu_{2}\right)$.

Testing the variance equality hypotheses, it is concluded that the variances are different so the $t$-test for arithmetic means for unequal variance was used.

Tablica 7 t-test: two-sample assuming unequal variances

\begin{tabular}{|c|c|c|}
\hline & $\Delta m_{\mathrm{SA} 516 \mathrm{Gr} .70}$ & $\Delta m_{\mathrm{X} 6 \mathrm{CrNiT} 18-10}$ \\
\hline Mean & $\mathbf{0 , 2 7 6 5 1 3}$ & $\mathbf{0 , 0 0 1 8 3 8}$ \\
\hline Variance & 0,021900 & 0,000001 \\
\hline Observations & 8 & 8 \\
\hline df & 7 & \\
\hline $\boldsymbol{t}$ Statistic & $\mathbf{5 , 2 4 9 6 6 6}$ & \\
\hline$P(T \leq t)$ one-tail & 0,000593 & \\
\hline$t$ Critical one-tail & 1,894579 & \\
\hline$P(T \leq t)$ two-tail & 0,001187 & \\
\hline $\boldsymbol{t}$ Critical two-tail & $\mathbf{2 , 3 6 4 6 2 4}$ & \\
Note: This symbol $\leq$ in Excel is $<=($ e.g. $\mathrm{T}<=\mathrm{t})$. \\
\end{tabular}

Tab. 7 shows that the calculated value of $t$ statistical $(5,249)$ is greater than the critical value of $t$ critical two tail $(2,364)$, i.e. it is outside the range of $-2,364$ to 2,364 and rejects the null hypothesis $H_{0}$. By testing the hypotheses, it can be concluded that there are significant differences in the average values of mass loss for both types of materials, that is, the proportion of alloying elements significantly affects the corrosion process flow.

\section{CONCLUSION}

Statistical analysis of the experimental data obtained by testing two types of materials under aggressive sodium chloride $(\mathrm{NaCl})$ conditions of the salt chamber was performed for the purpose of determining their corrosion resistance. One of the test materials is general structural steel SA516 Gr.70, while the other is austenitic stainless steel X6CrNiTi18-10. The aims of the paper were to obtain regression models for determining the mass loss depending on the exposure time of the test samples to the aggressive sodium chloride atmosphere, determination of the corrosion process flow and determination of the influence of alloying elements on the corrosion resistance.

Regression models with high coefficient of determination were obtained for both materials. For the model of the material SA516 Gr.70 $R^{2}$ is 0,9915 , and for the model of the material X6CrNiTi18-10 $R^{2}$ is 0,949 . The resulting models will well predict mass loss depending on the exposure time to the sodium chloride-rich aggressive atmosphere, as it was evidenced by the analysis of variance of the obtained models. It is clearly seen that the material SA516 Gr.70 has a linear, while X6CrNiTi18-10 material has a slow corrosion process flow. This can be further linked to the chemical composition of the tested materials. The $t$-test has shown that there is a significant difference in the average values of mass loss for both types of material. The proportion of alloying elements plays a significant role during the corrosion process. Due to the high content of alloying elements in the steel X6CrNiTi18-10, it has better corrosion properties and produces corrosion products that are sufficiently stable on the surface of the material. Because of that, it inhibits the emergence of new corrosion mechanisms, resulting in a slow corrosion process flow and slow decay of the structural material.

\section{LITERATURE}

[1] Peng, S., Xie, S.-K., Luc, J.-T., \& Zhang, L.-C. (2017). Surface characteristics and corrosion resistance of spangle on hot-dip galvanized coating. Journal of Alloys and Compounds, 728, 1002-1008. https://doi.org/10.1016/j.jallcom.2017.09.091

[2] Esih, I. (2010). Osnove površinske zaštite. Fakultet strojarstva i brodogradnje, Zagreb.

[3] Rokkam, S., Gunzburger, M., Brothers, M., Phan, N., \& Goel, K. (2019). A nonlocal peridynamics modeling approach for corrosion damage and crack propagation. Theoretical and Applied Fracture Mechanics, 101, 373-387. https://doi.org/10.1016/j.tafmec.2019.03.010

[4] Sun, B. (2018). A continuum model for damage evolution simulation of the high strenght bridge wires due to corrosion fatigue. Journal of Constructional Steel Research, 146, 7683. https://doi.org/10.1016/j.jcsr.2018.03.031

[5] Kanesund, J., Brodin, H., \& Johansson, S. (2019). Hot corrosion influence on deformation and damage mechanisms in turbine blades made of IN-792 during service. Engineering Failure Analysis, 96, 118-129. https://doi.org/10.1016/j.engfailanal.2018.10.004

[6] Lavanya, M., Murthy, V. R., \& Rao, P. (2018). Electrochemical investigation of erosion-corrosion behavior of 6061 aluminum alloy in marine environment. Tribology in Industry, 40(4), 552-564. https://doi.org/10.24874/ti.2018.40.04.04

[7] Liptakova, T., Alaskari, A., Trsko, L., \& Dundekova, S. (2017). Corrosion resistance of AISI 316Ti stainless steel subjected to shot peening with and without pickling in various chloride environments. Transactions of FAMENA, 41(3), 81-90. https://doi.org/10.21278/TOF.41307

[8] Kostadin, T., Cukor, G., \& Jakovljevic, S. (2017). Analysis of corrosion resistance when turning martensitic stainless 
steel X20Cr13 under chilled air-cooling. Advances in Production Engineering \& Management, (12)2, 105-114. https://doi.org/10.14743/apem2017.2.243

[9] Vrsalovic, L., Ivanic, I., Cudina, D., Lokas, L., Kozuh, S., \& Gojic, M. (2017). The influence of chloride ion concentration on the corrosion behavior of the CuAlNi alloy. Tehnicki glasnik-Technical Journal, 11(3), 67-72.

[10] Zaharia, S. M., Lancea, C., Chicos, L. A., Pop, M. A., Caputo, G., \& Serra, E. (2017). Mechanical properties and corrosion behaviour of $316 \mathrm{~L}$ stainless steel honeycomb cellular cores manufactured by selective laser melting. Transactions of FAMENA, 41(4), 11-24. https://doi.org/10.21278/TOF.41402

[11] Soares, C. G., Garbatov, Y., Zayed, A., \& Wang, G. (2009). Influence of environmental factors on corrosion of ship structures in marine atmosphere. Corrosion Science, 51, 2014-2026.https://doi.org/10.1016/j.corsci.2009.05.028

[12] Yan, L., Xiao, K., Yi, P., Dong, C., Wu, J., Bai, Z., Mao, C., Jiang, L., \& Li, X. (2017). The corrosion behavior of PCBImAg in industry polluted marine atmosphere environment. Materials and Design, 115, 404-414. https://doi.org/10.1016/..matdes.2016.11.074

[13] Diaz, I., Cano, H., De la Fuente, D., Chico, B., Vega, J. M., \& Morcillo, M. (2013). Atmospheric corrosion of Niadvanced weathering steels in marine atmospheres of moderate salinity. Corrosion Science, 76, 348-360 https://doi.org/10.1016/j.corsci.2013.06.053

[14] Chen, F. F., Breedon, M., Sapper, E. D., Ganther, W., Lau, D., \& Cole, I. (2017). A microclimate model to simulate neutral salt spray testing for corrosion inhibitor evaluation and functional coating development. Progress in Organic Coatings, 111, 327-335. https://doi.org/10.1016/j.porgcoat.2017.06.010

[15] Šolić, T., Marić, D., Duspara, M., \& Samardžić, I. (2018). Analysis of plated layer's effect on the structure resistance to corrosion. Metalurgija, 57 (4), 327-329. https://hrcak.srce.hr/201755

[16] Li, F., Zhang, W., Gao, L., \& Gao, H. (2016). The coupled effects of salt-spray corrosion, electrical current and mechanical load on the electrical and fatigue properties of COG assembly. Microelectronics Reliability, 66, 92-97. https://doi.org/10.1016/j.microrel.2016.10.010

[17] Wang, Y., Huang, Z., Yan, Q., Liu, C., Liu, P., Zhang, Y., Guo, C., Jiang, G., \& Shen, D. (2016). Corrosion behaviors and effects of corrosion products of plasma electrolytic oxidation coated AZ31 magnesium alloy under the salt spray corrosion test. Applied Surface Science, 378, 435-442. https://doi.org/10.1016/j.apsusc.2016.04.011

[18] Gimeno, M. J., Chamorro, S., March, R., Oro, E., Perez, P., Gracenea, J., \& Suay, J. (2014). Anticorrosive properties enhancement by means of phosphate pigments in an epoxy $2 \mathrm{k}$ coating. Assessment by NSS and ACET. Progress in Organic Coatings, 77 (12), 2024-2030. https://doi.org/10.1016/j.porgcoat.2014.04.004

[19] Wu, Q., Chen, X., Fan, Z., Nie, D., \& Wei, R. (2017). Corrosion fatigue behavior of FV520B steel in water and salt-spray environments. Engineering Failure Analysis, 79, 422-430. https://doi.org/10.1016/j.engfailanal.2017.05.012

[20] Ragunath, S., Velmurugan, C., \& Kannan, T. (2014). Experimental investigation on corrosive behavior of boiler material using polarization technique. Procedia material science, 5, 1274-1280. https://doi.org/10.1016/j.mspro.2014.07.439

[21] Krella, A. K. \& Krupa, A. (2018) Effect of cavitation intensity on degradation of X6CrNiTi18-10 stainless steel. Wear, 408-409, 180-189. https://doi.org/10.1016/j.wear.2018.05.015

[22] Juraga, I., Alar, V. \& Stojanović, I. (2014). Korozija i zaštita premazima. Fakultet strojarstva i brodogradnje, Zagreb.
[23] HRN EN ISO 9227:2017, Ispitivanje korozije u umjetnoj atmosferi - Metoda ispitivanja u slanoj komori (ISO 9227:2017; EN ISO 9227:2017); Corrosion tests in artificial atmospheres - Salt spray tests (ISO 9227:2017; EN ISO 9227:2017), (2017). Hrvatski zavod za norme, Zagreb.

\section{Contact information:}

Tomislav ŠoLIĆ, mag. ing. mech., Assistant Mechanical Engineering Faculty in SlavonskiBrod, Josip Juraj Strossmayer University of Osijek, Trg I. B. Mažuranić 2, HR-35000 Slavonski Brod, Croatia E-mail: tsolic@sfsb.hr

Sara HAVRLIŠAN, dr. sc., Postdoctoral Researcher (Corresponding Author) Mechanical Engineering Faculty in SlavonskiBrod, Josip Juraj Strossmayer University of Osijek,

Trg I. B. Mažuranić 2, HR-35000 Slavonski Brod, Croatia

E-mail: shavrlisan@sfsb.hr

Dejan MARIĆ, mag. ing. mech., Assistant Mechanical Engineering Faculty in SlavonskiBrod, Josip Juraj Strossmayer University of Osijek, Trg I. B. Mažuranić 2, HR-35000 Slavonski Brod, Croatia E-mail:dmaric@sfsb.hr

Ivan SAMARDŽIĆ, prof. dr. sc., Full Professor Mechanical Engineering Faculty in Slavonski Brod, Josip Juraj Strossmayer University of Osijek,

Trg I. B. Mažuranić 2, HR-35000 SlavonskiBrod, Croatia E-mail: isamardzic@sfsb.hr 